Article

\title{
Construction of Luminogen Exhibiting Multicolored Emission Switching through Combination of Twisted Conjugation Core and Donor-Acceptor Units
}

\author{
Haiyan Tian ${ }^{+}$(D), Xi Tang ${ }^{+}$(D) and Yong Qiang Dong * \\ Beijing Key Laboratory of Energy Conversion and Storage Materials, Department of Chemistry, \\ Beijing Normal University, Beijing 100875, China; 201431150053@mail.bnu.edu.cn (H.T.); \\ hptangxi@163.com (X.T.) \\ * Correspondence: dongyq@bnu.edu.cn; Tel.: +86-10-5880-6896 \\ t These authors contributed equally to this work.
}

Received: 17 November 2017; Accepted: 11 December 2017; Published: 14 December 2017

\begin{abstract}
Stimuli responsive luminescent materials, especially those exhibiting multicolor emission switching, have potential application in sensor, optical recording, security ink, and anti-counterfeit label. Through combination of twisted conjugation core and donor and acceptor units, a luminogen (2-(bis(4-(carbazol-9-yl)phenyl)methylene)malononitrile (1) was synthesized. Luminogen $\mathbf{1}$ can form three kinds of crystals emitting green (1GC, $\lambda_{\mathrm{em}}=506 \mathrm{~nm}, \Phi_{\mathrm{F}}=19.8 \%$ ), yellow-green (1YC, $\left.\lambda_{\mathrm{em}}=537 \mathrm{~nm}, \Phi_{\mathrm{F}}=17.8 \%\right)$, and orange (1OC, $\left.\lambda_{\mathrm{em}}=585 \mathrm{~nm}, \Phi_{\mathrm{F}}=30.0 \%\right)$ light upon $365 \mathrm{~nm} \mathrm{UV}$ illumination. The emission of amorphous solid of $\mathbf{1}(\mathbf{1 A m})$ overlaps with that of $10 C\left(\lambda_{\mathrm{em}}=585 \mathrm{~nm}\right)$, with quantum yield of $13.9 \%$, which is seldom reported. Emission of $\mathbf{1}$ can be switched among green, yellow-green, and orange through morphology modulation upon exposure to thermal, solvent vapor, or mechanical stimuli. Finally, its potential application in optical recording was also investigated.
\end{abstract}

Keywords: aggregation-induced emission; multicolor emission switching; mechanochromic fluorescence; optical recording

\section{Introduction}

Stimuli responsive luminescent materials have attracted much attention in recent years due to their potential application in optical storage [1], optoelectronic devices [2-4], security papers [5], and sensor [6-15]. The emission colors and intensities of these materials can be tuned by external stimuli, such as heat [16-18], solvent vapor [19-21], and mechanical perturbation (including grinding, shearing, smashing, or stretching) [22-26]. However, their practical applications are limited because emissions of many luminogens are weakened or totally quenched in the solid state, which is known as aggregation-caused quenching (ACQ) $[27,28]$.

In 2001, Tang found that a series of propeller-like luminogens were nearly nonemissive in solution but emitted intensely upon aggregation, thus, Tang coined this phenomenon as aggregation-induced emission (AIE) $[29,30]$. The phenomenon was mainly ascribed to the restriction of intramolecular motions (RIM) process [31]. In 2005, Tang and coworkers found that crystals of some AIE luminogens exhibited more intense emission than their amorphous solid, and they coined this phenomenon as crystallization induced emission enhancement (CIEE) [32,33]. The molecules of AIE luminogens pack loosely and can easily form varied morphologies due to their flexible conformations. The loose packing patterns of those CIEE active luminogens also facilitate the reversible transformation between different morphologies. Thus, the emission of many CIEE active luminogens can be switched between different states through morphological modulation [34-36]. 
Although many stimuli responsive luminogens that are based on CIEE activity have been developed [37-44], emission of most of them can only be switched between two states through morphology tuning between amorphous and crystalline states [23,25,41,44-46]. Luminogens exhibiting multicolored switching are rather rare due to the lack of design strategy, in spite of their potential for improving anti-fake complexity and density of optical storage.

$D-\pi$-A type materials usually exhibit unique fluorescence properties due to their intramolecular charge transfer (ICT) transitions [47-49]. However, ACQ often takes place in the condensed phases for many D- $\pi$-A luminogens, limiting their real-world applications. In this paper, we constructed a symmetric compound 2-(bis(4-(9H-carbazol-9-yl)phenyl)methylene)malononitrile (1), with electron donor (carbazole) and acceptor (two cyano groups). Luminogen $\mathbf{1}$ is AIE and CIEE active and can form four morphologies with varied emissions and efficiencies. In particular, luminogen 1 can be switched among three different crystalline forms with green, yellow-green, and orange emission, which is rarely reported. Luminogen $\mathbf{1}$ exhibits mechanochromic luminescence and its potential application in optical recording was investigated.

\section{Results and Discussion}

\subsection{Synthsis of Compound $\mathbf{1}$}

Compound 1 was prepared according to the synthetic procedures shown in Scheme 1, giving a yield of $86 \%$. The structure of 1 was characterized by ${ }^{1} \mathrm{H}-\mathrm{NMR},{ }^{13} \mathrm{C}-\mathrm{NMR}$, and HRMS spectroscopies (Figures S1-S4). The detailed synthetic procedures can be found in the Materials and Methods of this paper. Thermal gravimetric analysis (TGA) showed that compound 1 possessed good thermal stability, losing $5 \%$ of its weight under nitrogen at about $411{ }^{\circ} \mathrm{C}$ (Figure S5).

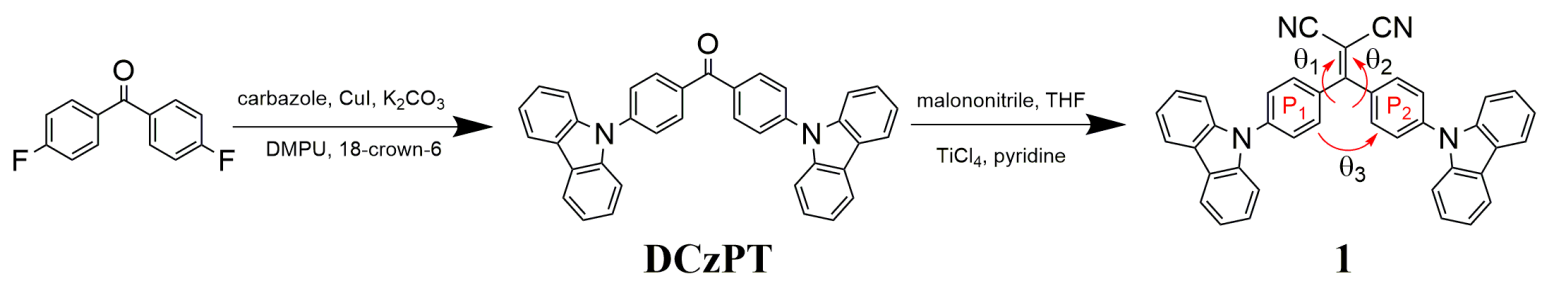

Scheme 1. Synthesis routes to compound 1.

\subsection{The UV-Vis Absorption and Aggregation-Induced Emission (AIE)}

The UV-Vis absorption of $\mathbf{1}$ in dichloromethane (DCM) was showed in Figure S6. The maximum absorption of 1 locates at $414 \mathrm{~nm}$ and the molar absorption coefficient $\varepsilon$ is $15,707 \mathrm{~L} /(\mathrm{mol} \cdot \mathrm{cm})$, which is quite high among D- $\pi$-A compounds. Compound $\mathbf{1}$ is nearly nonemissive when it is dissolved in acetonitrile, while the emission is turned on upon addition of large amount of water to the solution. Compound $\mathbf{1}$ is hydrophobic and forms aggregates upon addition of large amount of water. That is, compound $\mathbf{1}$ is AIE active (Figure S7).

\subsection{Emission of the Three Crystals and the Amorphous Solid}

The photophysical properties of luminogen $\mathbf{1}$ in the solid state were further studied because luminogens are generally used in solid state in their real applications. We obtained three kinds of single crystals 1GC $\left(\lambda_{\mathrm{em}}=506 \mathrm{~nm}, \Phi_{\mathrm{F}}=19.8 \%\right.$, Figure $\left.1 \mathrm{~A}(\mathrm{a})\right), 1 \mathrm{YC}\left(\lambda_{\mathrm{em}}=537 \mathrm{~nm}, \Phi_{\mathrm{F}}=17.8 \%\right.$, Figure 1A (b)) and 10C $\left(\lambda_{\mathrm{em}}=585 \mathrm{~nm}, \Phi_{\mathrm{F}}=30.0 \%\right.$, Figure $\left.1 \mathrm{~A}(\mathrm{c})\right)$ through slow evaporation the mixture of DCM/ $n$-hexane (volume, 3:1), THF/ $n$-hexane (volume, 2:1) and EA/ $n$-hexane (volume, 1:1), respectively, at room temperature under the rigorous exclusion of light. 1GC and 1OC belong to orthorhombic system without any solvent molecule in the lattice; 1YC belongs to monoclinic system with tetrahydrofuran (THF) molecules in crystal lattice, and the molecular molar ratio of $\mathbf{1}$ versus THF 
is 1:1, which was also confirmed by ${ }^{1} \mathrm{H}-\mathrm{NMR}$ (see Figure S1). The schematic illustration of three crystals is shown in Scheme 2.
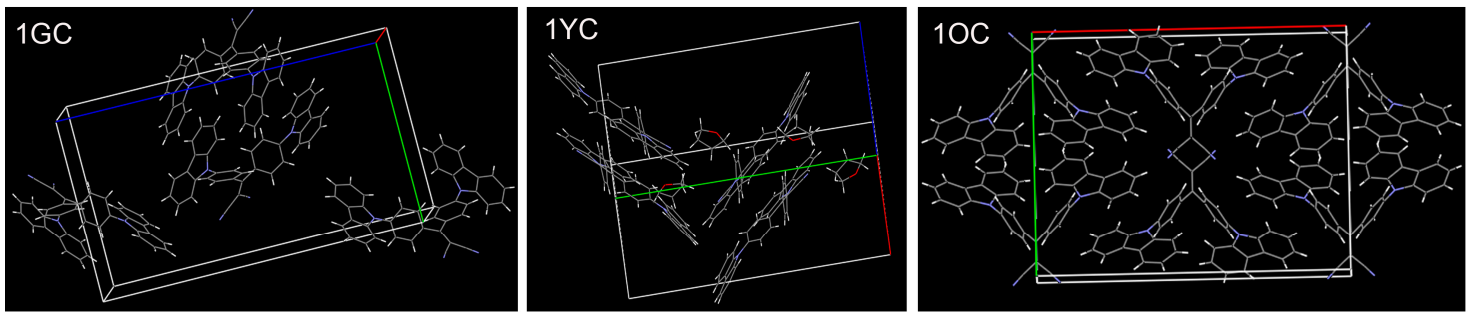

Scheme 2. Schematic illustration of the three single crystals of 1GC, 1YC, and 1OC.

In addition to the single crystal structure and quantum efficiency, photoluminescence (PL) spectra (Figure 1B), differential scanning calorimetry (DSC) curves (Figure 1C), and Powder X-Ray diffraction (PXRD) patterns (Figure 1D) of 10C and 1YC also reveal that they are different crystalline phases. Unfortunately, we cannot obtain enough 1GC for the measurements of DSC and PXRD.
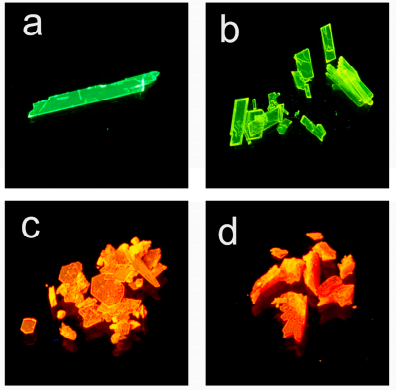

A

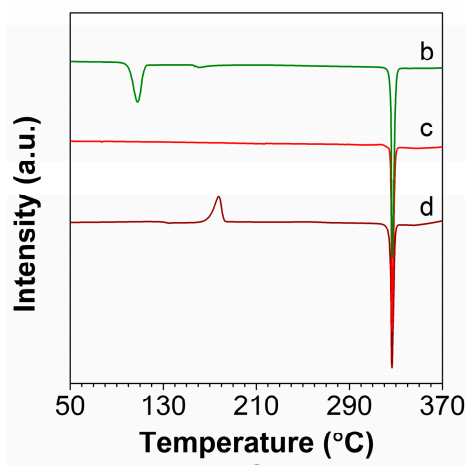

C

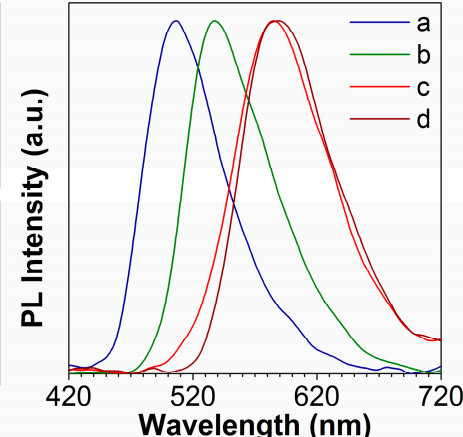

B

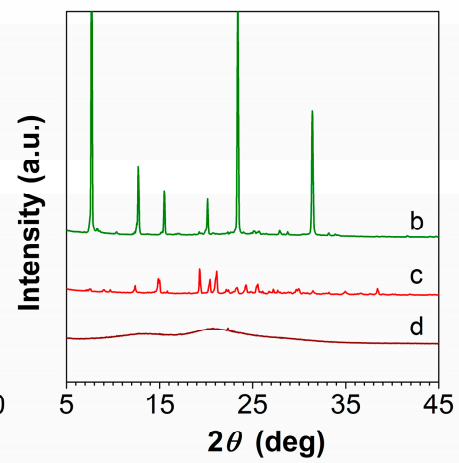

D

Figure 1. (A) Photos of compound 1 in different states: (a) 1GC, (b) 1YC, (c) 1OC and (d) 1Am; (B) Normalized PL spectra of samples (a-d), excitation wavelength: $370 \mathrm{~nm}$; (C) differential scanning calorimetry (DSC) curves and (D) Powder X-Ray diffraction (PXRD) patterns of samples (b-d).

Many AIE luminogens are CIEE active, so we prepared the amorphous sample of luminogen 1 $\left(\mathbf{1 A m}, \lambda_{\mathrm{em}}=585 \mathrm{~nm}, \Phi_{\mathrm{F}}=13.9 \%\right.$, Figure $\left.1 \mathrm{~A}(\mathrm{~d})\right)$ by quenching its melt with liquid nitrogen, and the amorphous essence of $\mathbf{1 A m}$ was verified by the absence of diffraction peaks in its PXRD pattern (Figure 1D, line d). Exothermic peak at $177^{\circ} \mathrm{C}$ in the DSC curve of $\mathbf{1 A m}$ (Figure 1C, line d) indicates the crystallization transition. Thus, luminogen 1 exhibits four morphologies, depending on different molecular packing modes in the solid state. The optical properties such as florescence lifetime and quantum yield of four aggregate states were summarized in Table 1. 
Table 1. Optical properties of luminogen $\mathbf{1}$ in the various aggregate states.

\begin{tabular}{cccc}
\hline Samples & ${ }^{\mathbf{a}} \boldsymbol{\lambda}_{\text {em }}(\mathbf{n m})$ & ${ }^{\mathbf{b}} \boldsymbol{\Phi}_{\mathbf{F}}(\mathbf{\%})$ & ${ }^{\mathbf{c}}<\tau>$ (ns) \\
\hline 1GC & 506 & 19.8 & 6.59 \\
1YC & 537 & 17.8 & 18.66 \\
1OC & 585 & 30.0 & 23.23 \\
1Am & 585 & 13.9 & 17.76
\end{tabular}

${ }^{\mathrm{a}} \lambda_{\mathrm{em}}=$ Emission maximum. ${ }^{\mathrm{b}} \Phi_{\mathrm{F}}=$ Fluorescence quantum yield determined using a calibrated integrating sphere, excited at $370 \mathrm{~nm}$. ${ }^{\mathrm{c}}$ The mean lifetime $\langle\tau\rangle$ was calculated according to $\langle\tau\rangle=\left(A_{1} \tau_{1}+A_{2} \tau_{2}\right) /\left(A_{1}+A_{2}\right)$.

The availability of several single crystals based on one luminogen provides the possibility to study the effect of molecular conformation and packing pattern on the photophysical properties of the luminogen, ruling out the effect of chemical structure. The extraordinary twisted molecular conformation of $\mathbf{1}$ in crystals rule out the strong intermolecular interactions, such as $\pi-\pi$ stacking $[22,23]$ or $\mathrm{H} / \mathrm{J}$ aggregates $[50,51]$. Thus, the difference of emission colors among the three crystals may be attributed to the difference of molecular conformation. Obviously, the dihedral angles of $10 \mathrm{C}$ are smaller than that of $1 \mathrm{GC}$, suggesting better coplanarity and greater conjugation of $10 \mathrm{C}$, which is responsible for red-shifted emission of 10C. The dihedral angles of 1YC are smallest among three crystals, however, its emission color falls in between 1GC and 1OC (Table S4). This abnormal phenomenon may be caused by the THF molecules in 1YC [52]. 1Am exhibits similar emission to 1OC, which may be caused by the similar molecular conformation in different molecular packing modes.

The crystals of 1 show higher quantum yields than $\mathbf{1 A m}$, as molecules in crystalline states pack more tightly than those in $\mathbf{1 A m}$, which may further hinder the rotation of phenyl rings and block the nonradiative transmission pathway. $10 \mathrm{C}$ exhibits strongest emission among three crystals, closely followed by 1GC, finally 1 YC, which is in good agreement with the number of interactions existing in crystals: four $\mathrm{C} \equiv \mathrm{N} \cdots \mathrm{H}$ and thirty six $\mathrm{C}-\mathrm{H} \cdots \pi$ interactions in $10 \mathrm{C}$, two $\mathrm{C} \equiv \mathrm{N} \cdots \mathrm{H}$ and twenty two $\mathrm{C}-\mathrm{H} \cdots \pi$ interactions in $\mathbf{1 G C}$ and two $\mathrm{C}-\mathrm{H} \cdots \mathrm{O}$, nine $\mathrm{C} \equiv \mathrm{N}-\mathrm{H}$ and twelve $\mathrm{C}-\mathrm{H} \cdots \pi$ interactions in 1 YC (Figures S8-S10 and Tables S5-S7).

\subsection{Tuning the Emission of $\mathbf{1}$ in the Solid State}

Emission of many CIEE active luminogens can be switched between two states through morphology tuning between amorphous and crystalline states. However, examples of multicolored emission switching are rather rare. If we could modulate the molecular packing patterns of $\mathbf{1}$, then we may switch its emission in the solid state among multiple colors [53].

Normally, an amorphous solid will crystallize upon heating or exposure to solvent vapor. Inspired by the exothermic peak at $177^{\circ} \mathrm{C}$ in the DSC curve of $\mathbf{1 A m}$, we heated $\mathbf{1 A m}$ at $200{ }^{\circ} \mathrm{C}$. However, 1Am exhibited nearly no change in emission color (Figure 2A, (a) to (g)). Although 1Am and 1OC are both orange emissive, the transformation of $1 \mathrm{Am}$ to $10 \mathrm{C}$ upon heating was verified by the overlapping of the DSC curves and PXRD patterns (lines a and $g$ in Figure 2C,D). In addition to thermal treatment, we exposed $\mathbf{1 A m}$ to solvent vapor, finding that $\mathbf{1 A m}$ transformed to $10 \mathrm{C}$ upon exposure to ethyl acetate (EA) (Figure 2A, (a) to (b)), while to 1YC upon exposure to THF (Figure 2A, (a) to (c)). The transformation was further verified by PL spectra, DSC curves, and PXRD patterns (lines $\mathrm{b}$ and $\mathrm{c}$ in Figure 2B-D). Therefore, the weak orange emissive 1Am can be converted to bright orange $1 \mathrm{OC}$ upon heating at $200{ }^{\circ} \mathrm{C}$ or fuming with EA vapor, while to yellow-green 1YC when fumed with THF. We could not obtain 1GC through solvent fuming though we have tried many solvents. 1Am can be re-obtained by quenching the melt of 1 with liquid nitrogen. Thus, we can switch the emission of 1 reversibly between weak orange and bright orange, or between weak orange and yellow-green.

In addition to switching 1 between amorphous and crystalline states, we tried to modulate luminogen 1 among multiple crystalline states. The endothermic peak at around $128{ }^{\circ} \mathrm{C}$ in the DSC curve of 1YC (line $\mathrm{d}$ in Figure 2C) indicates a crystal to crystal phase transition, so we heated the 1YC at $140{ }^{\circ} \mathrm{C}$ and found that the emission of 1 YC changed from yellow-green to orange (Figure 2A, 
(d) to (e)). The PL spectrum, DSC curve, and PXRD pattern of the heated 1YC fit well with those of 1OC, indicating that $\mathbf{1 Y C}$ had transformed to $10 \mathrm{C}$ upon heating at $140{ }^{\circ} \mathrm{C}$. However, no thermal effect was observed in the DSC curve of $10 \mathrm{C}$ before melt, therefore, 10C could not convert back to 1YC by thermal treatment. In addition to the thermal treatment, we tried to achieve the transformation among different crystalline phases of 1 through solvent fuming. Fortunately, 1YC turned to 1OC upon fuming with EA vapor (Figure 2A, (d) to (g)), while 1OC can transform back to 1YC upon exposure to THF vapor (Figure 2A, (e) to (d) and (f) to (d)). This transformation was easily distinguished by the naked eye and verified by PL spectra, DSC curves, and PXRD patterns (Figure 2B-D).

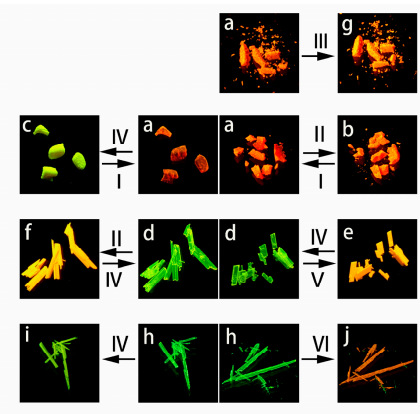

A

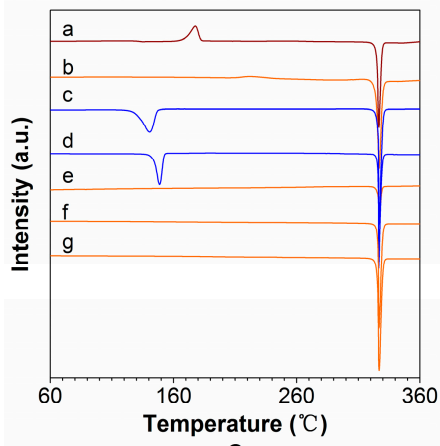

C

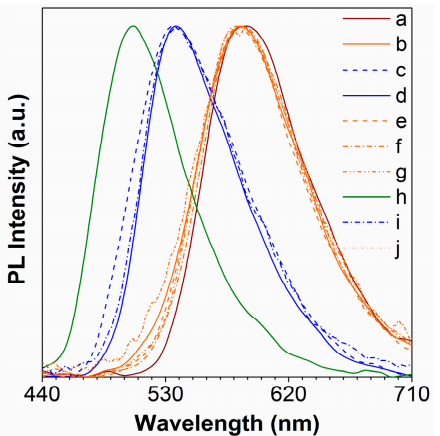

B

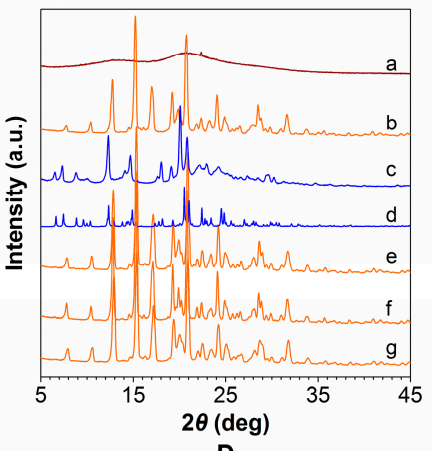

D

Figure 2. (A) Photographs of samples (a-j) under the 365 UV illumination: (a) 1Am, (b) 1Am fumed with ethyl acetate (EA), (c) 1Am fumed with tetrahydrofuran (THF), (d) 1YC, (e) 1YC annealed at $140{ }^{\circ} \mathrm{C}$, (f) 1 YC fumed with EA, (g) 1Am heated at $200^{\circ} \mathrm{C}$, (h) 1GC, (i) 1GC fumed with THF, (j) 1GC fumed with DCM; (B) Normalized PL spectra of samples $(\mathbf{a}-\mathbf{j})$, excitation wavelength: $370 \mathrm{~nm}$; (C) DSC curves and (D) PXRD patterns of samples (a-g). Conditions: I: heating to melt and quickly cooled by liquid nitrogen; II: fuming with EA; III: heating at $200^{\circ} \mathrm{C}$; IV: fuming with THF; V: heating at $140{ }^{\circ} \mathrm{C}$; and, VI: fuming with DCM.

As aforementioned, we obtained 1YC in THF/n-hexane and found THF molecules existing in the 1YC, however, 1OC had no solvent molecule in the lattice. So, we guessed it was the loss of THF molecules that led to the transformation from 1YC to 1OC. In order to verify our assumption, we heated $1 \mathrm{YC}$ at $90{ }^{\circ} \mathrm{C}$ in vacuum for some time and found the yellow-green crystals changed to orange. This change was recorded by ${ }^{1} \mathrm{H}-\mathrm{NMR}$ (Figures $\mathrm{S} 1$ and S2). We heated the $1 \mathrm{YC}$ at $90{ }^{\circ} \mathrm{C}$ so that the THF molecules were removed without changing crystal phase (the crystal transformation temperature is about $128^{\circ} \mathrm{C}$ ). Therefore, the reason of 1YC to 1 OC is indeed the loss of THF molecules; when the THF molecules accessed into 1OC again, 1YC was obtained again. Therefore, we can draw the conclusion that the THF molecules can change molecular conformation and packing mode of 1YC and 1OC [54]. Inspired by above phenomenon, we also obtained 1YC by fuming 1GC with THF vapor (Figure 2A, (h) to (i)), while we got 10C by fuming 1GC with DCM (Figure 2A, (h) to (j)), which was verified by the PL spectra (Figure 2B). Unfortunately, we could not measure the DSC curves and PXRD patterns about the transformation process of 1GC because of few 1GC we obtained. Thus, the emission of luminogen 
$\mathbf{1}$ can be switched reversibly between orange (1OC) and yellow-green (1YC) by repeating annealing at $140{ }^{\circ} \mathrm{C}$ (or fuming with EA vapor) and exposure to THF vapor. The reversible transformation process can be repeated many times due to the physical nature of the process (Figures S12-S14). Besides, we achieve the switching of 1GC to 1OC by fuming with DCM or 1GC to 1YC upon exposure to THF vapor. Thus, we can switch the emission of a single compound among three crystals in the solid state, which is rarely reported.

\subsection{Mechanochromic Fluorescence}

Mechanical stimuli normally amorphizes crystals of luminogens, and the amorphous solid will crystallize again upon heating or fuming with solvent vapor, thus, luminogen $\mathbf{1}$ may exhibit mechanochromic luminescence and its emission may be reversibly switched between different colors by thermal, mechanical, and solvent stimuli.

The yellow-green emissive 1YC turned to orange upon grinding and the PL spectrum of the ground powder overlapped with that of $\mathbf{1 A m}$. In addition, both the exothermal peak in the DSC curve and absence of diffraction peaks in PXRD pattern of the ground powder from 1YC suggested that 1YC had been amorphized by grinding (Figure 3). As aforementioned, 1Am can transform to 1YC upon exposure to THF vapor; thus, we fumed the ground powder of 1 with THF. As we expected, the emission of the ground powder turned to yellow-green (Figure 3A), indicating that the ground powder turned to 1YC, which was verified by the PL spectrum, DSC curve, and PXRD pattern (line $\mathrm{b}$ in Figure 3B-D). Emission color and the PL spectrum of the ground powder did not change upon exposure to EA vapor or annealing at $185^{\circ} \mathrm{C}$, which was similar to 1Am (Figure 4A,B). However, the DSC curves and PXRD patterns of the ground powder after fuming or heating fit well with those of 10C (Figure 4C,D). Thus, luminogen 1 exhibits mechanochromic luminescence, and the emission of $\mathbf{1}$ can be reversibly switched between orange and yellow-green by alternate grinding and THF fuming process. The complexity of the transformation of the ground powder upon exposure to different external stimuli may afford its potential application in security ink and optical recording.
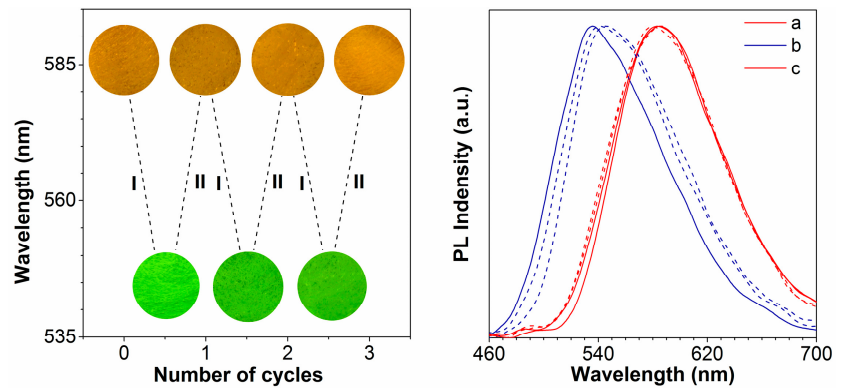

A
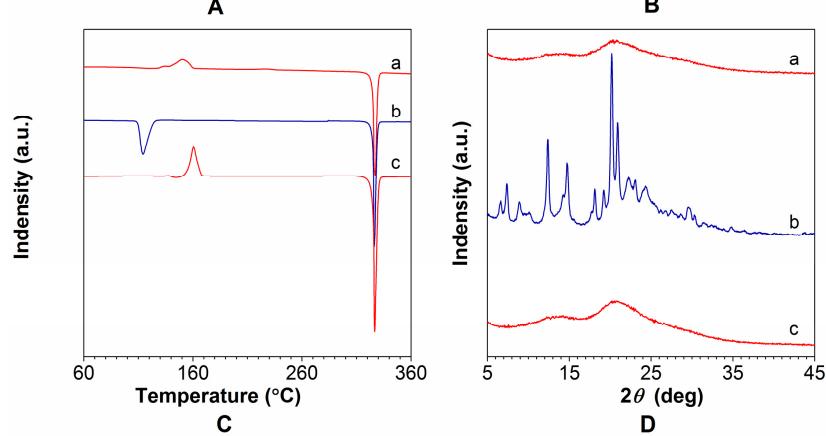

Figure 3. (A) Switching the fluorescence and photograph of $\mathbf{1}$ by repeated grinding (II) and fuming with THF (I) in the agate mortar; (B) Normalized PL spectra of ground powder and fumed solid of $\mathbf{1}$ in the three repeating cycles, the blue dotted lines: ground powder fumed with THF and the red dotted lines: ground powder, excitation wavelength: $370 \mathrm{~nm}$; (C) DSC curves and (D) PXRD patterns in the first cycle. (a) ground powder, (b) sample (a) fumed with THF, (c) sample (b) ground again. 

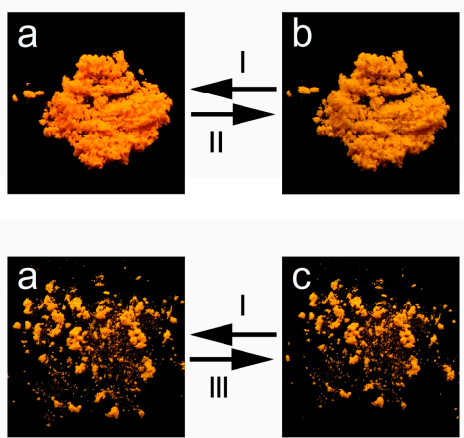

A

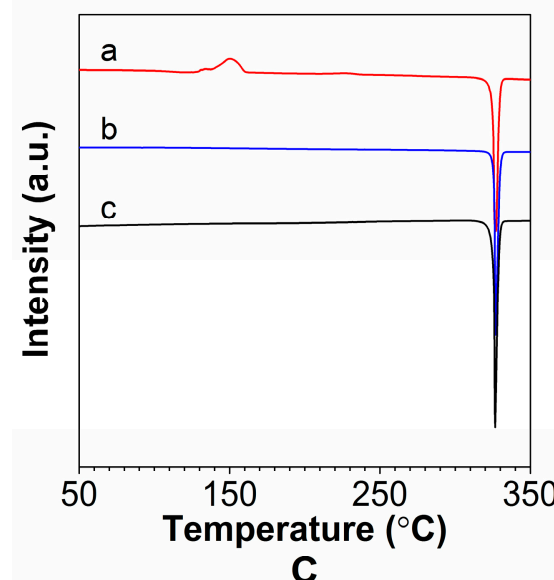

C
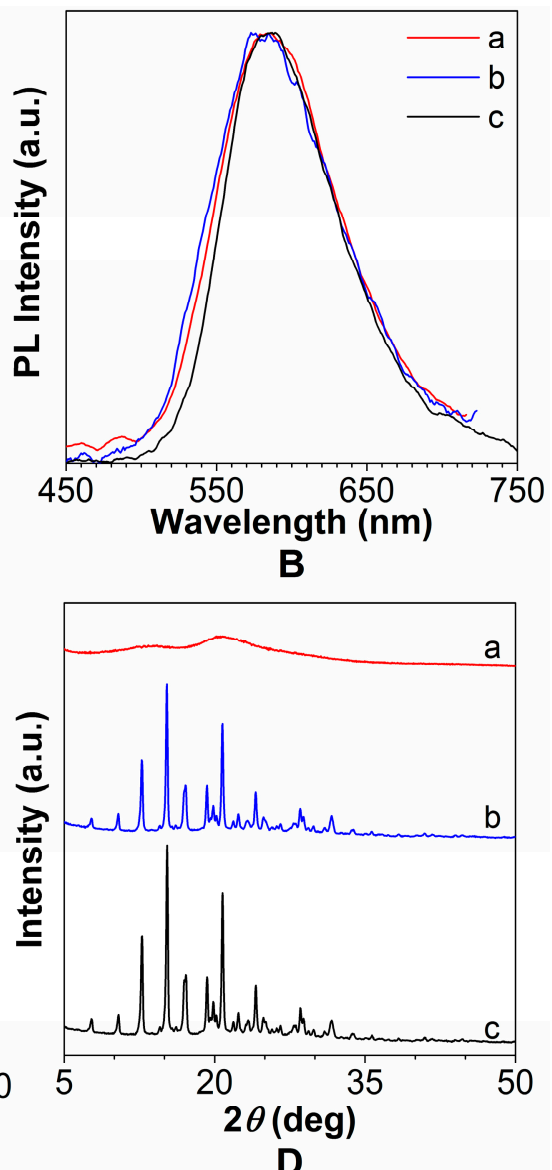

Figure 4. (A) Photographs of (a) ground solid from 1OC, (b) sample (a) fumed with EA and (c) sample (a) annealed at $185^{\circ} \mathrm{C}$; (B) Normalized PL spectra, (C) DSC curves, and (D) PXRD patterns of samples $(\mathbf{a}-\mathbf{c})$. Conditions: I: grinding; II: fuming with EA; III: heating at $185^{\circ} \mathrm{C}$.

\subsection{Application in Optical Recording}

The multicolored mechanochromic fluorescence of 1 prompts us to investigate its potential application as an optical recording material. Luminogen 1 was ground on one piece of weighing paper, and then the weak orange paper (Figure 5a) turned to bright orange (Figure $5 b$ ) after annealing at $185^{\circ} \mathrm{C}$. Then, we wrote " $\mathrm{M}$ " on the "paper", a weak orange " $\mathrm{M}$ " appeared on the bright orange background due to the amorphization of $10 \mathrm{C}$ in the sheared handwriting area (Figure 5c). The letter "M" disappeared when the "paper" was fumed with EA (Figure 5d), due to the transformation of 1 in the letter area from $\mathbf{1 A m}$ to $10 \mathrm{C}$. We rewrote " $\mathrm{M}$ " on the "paper", and then a weak orange "M" appeared again on the bright orange background (Figure 5e). When the "paper" was exposed upon THF vapor for $30 \mathrm{~min}$, a yellow-green " $\mathrm{M}$ " appeared on the orange background due to the transformation of $\mathbf{1}$ in the area of " $\mathrm{M}$ " from 1Am to 1YC (Figure 5f). However, the orange background kept unchanged in the process because the transformation of 1OC to 1YC is much slower than the transformation from amorphous solid to crystal. The whole "paper" turned to yellow-green when it was fumed with THF vapor for another $2.5 \mathrm{~h}$ (Figure $5 \mathrm{~g}$ ). We rewrote " $\mathrm{M}$ " on the "paper", an orange " $\mathrm{M}$ " appeared on the yellow-green background (Figure 5h) and the " $\mathrm{M}$ " disappeared when the "paper" was fumed with THF vapor for $10 \mathrm{~min}$ (Figure 5i). Finally, the yellow-green "paper" returned to bright orange when annealed at $140{ }^{\circ} \mathrm{C}$ for $1 \mathrm{~h}$ (Figure 5j). Compound 1 exhibits different response to different stimuli and the emission changes can be distinguished by the naked eyes, suggesting its potential application in anti-fake. 

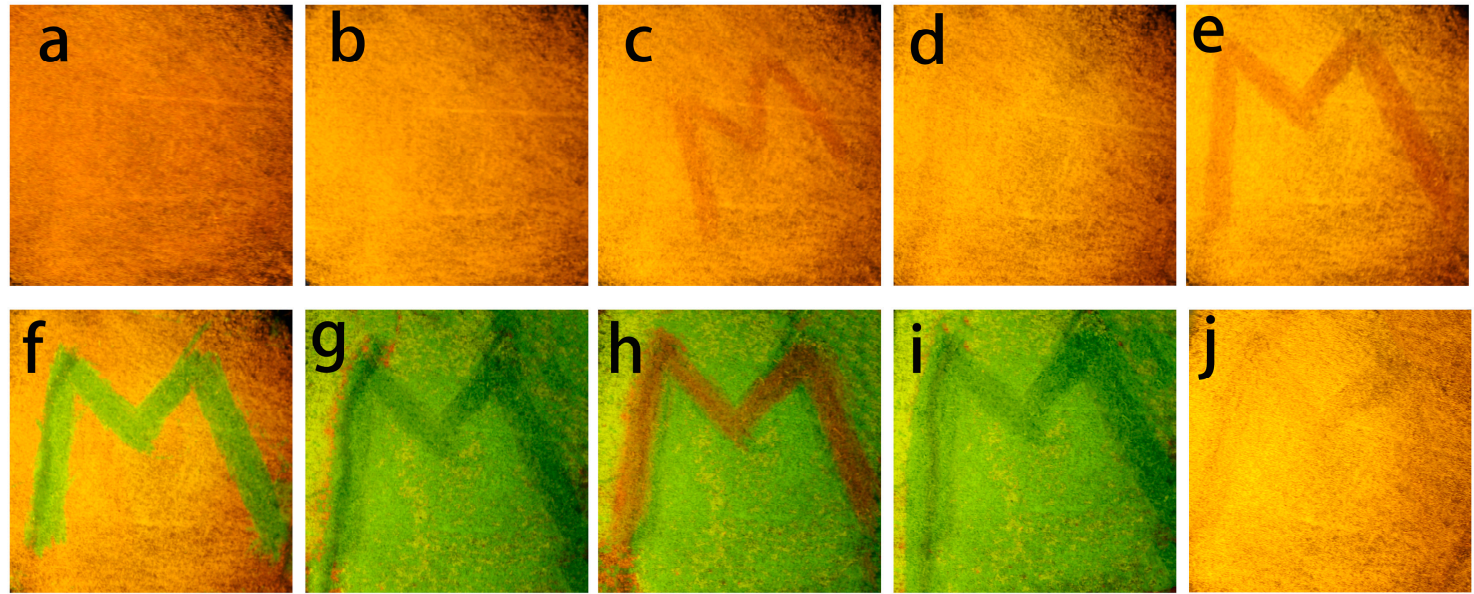

Figure 5. Procedures of writing and erasing process of using the weighing paper coated with 1, luminescent images were taken under $365 \mathrm{~nm}$ UV illumination: (a) 1 ground on weighing paper; (b) a annealed at $185^{\circ} \mathrm{C}$; (c) wrote " $\mathrm{M}$ " in b; (d) c fumed with EA; (e) rewrote " $\mathrm{M}$ " in d; (f) e fumed with THF for $30 \mathrm{~min}$; (g) f fumed with THF for 2.5 h; (h) wrote "M" in g; (i) h fumed with THF for $10 \mathrm{~min},(\mathbf{j}) \mathrm{i}$ annealed at $140{ }^{\circ} \mathrm{C}$ for $10 \mathrm{~min}$.

\section{Materials and Methods}

\subsection{Materials and Instruments}

All of the original material were commercially available and used without further purification. ${ }^{1} \mathrm{H}-\mathrm{NMR}$ and ${ }^{13} \mathrm{C}-\mathrm{NMR}$ spectra were measured on a Bruker AV III $400 \mathrm{MHz}$ Spectrometer (Bruker, Karlsruhe, Germany). Mass spectrum was recorded with an AB SCIEX Triple Top 5600 mass spectrometer (AB SCIEX, Framingham, MA, USA), equipped with a dual sprayer orthogonal electrospray source (Lock Spray). Thermal gravimeter analysis (TGA) was performed using a METTLER TGA/DSC instrument (Mettler, Greifensee, Switzerland) at a scanning rate of $10 \mathrm{~K} / \mathrm{min}$. UV-Vis absorption spectra were recorded on a Shimadzu UV-2450 recording spectrophotometer (Shimadzu, Kyoto, Japan). The fluorescence spectra were recorded on a VARIAN Cary Eclipse fluorescence spectrophotometer (Varian, Melbourne, Australia). Fluorescence quantum yield was recorded on Hamamatsu Quantaurus-QY C9220-02 (Quantaurus-QY, Hamamatsu, Japan) at room temperature with a calibrated integrating sphere system. Differential scanning calorimetry (DSC) curves were performed on a METTLER DSC 1 instrument (Mettler) at a heating rate of $10 \mathrm{~K} / \mathrm{min}$ from room temperature to $360{ }^{\circ} \mathrm{C}$ under nitrogen atmosphere. Powder X-Ray diffraction (PXRD) patterns were performed on a BDX-3000 (Beijing university electronic instrument factory, Beijing, China) with

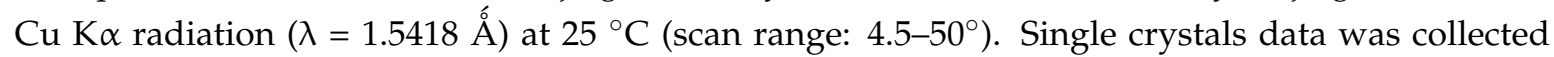
on a Bruker APEX-II CCD diffractometer (Bruker), using graphite monochromatic Mo K $\alpha$ radiation $(\lambda=0.71073 \AA$ Á). All of the photographs were taken by PENTAX K- 5 digital camera (PENTAX, Kyoto, Japan) and all photos in the same Figure were same exposure time. The thermal annealing process was carried out in oven. The amorphous powder of luminogens was prepared by heating the luminogens to melt with a heating gun and quenching the melt with liquid nitrogen.

\subsection{Synthesis of Compound 1}

Synthesis of bis(4-(9H-carbazol-9-yl)phenyl)methanone (DCzPT). Under an argon atmosphere, bis(4-fluorophenyl)methanone $(4.45 \mathrm{~g}, 20 \mathrm{mmol})$, carbazole $(17.3 \mathrm{~g}, 103 \mathrm{mmol})$, potassium carbonate $(5.02 \mathrm{~g}, 36 \mathrm{mmol}), \mathrm{CuI}(0.27 \mathrm{~g}, 14 \mathrm{mmol})$ and 18 -crown-6 $(0.17 \mathrm{~g}, 0.6 \mathrm{mmol})$ were added in a $1000 \mathrm{~mL}$ two-neck flask. The mixture was added into $1 \mathrm{~mL}$ DMPU and then heated up to $170{ }^{\circ} \mathrm{C}$ for $10 \mathrm{~h}$. After cooling to room temperature, the mixture was extracted with vast DCM and saturated 
$\mathrm{NaCl}$ solution until the water layer was neutral. The organic layer was dried over $\mathrm{MgSO}_{4}$ and was concentrated by a rotary evaporator. The crude product was separated by silica gel column chromatography (eluent: TCM $/ n$-hexane). Finally faint yellow-green solid was obtained in a yield of 68\%. ${ }^{1} \mathrm{H}-\mathrm{NMR}\left(400 \mathrm{MHz}, \mathrm{DMSO}-d_{6}\right), \delta(\mathrm{TMS}, \mathrm{ppm}): 8.29(\mathrm{~d}, 4 \mathrm{H}), 8.18(\mathrm{~d}, 4 \mathrm{H}), 7.92(\mathrm{~d}, 4 \mathrm{H}), 7.60(\mathrm{~d}$, $4 \mathrm{H}), 7.50(\mathrm{t}, 4 \mathrm{H}), 7.35(\mathrm{t}, 4 \mathrm{H}) .{ }^{13} \mathrm{C}-\mathrm{NMR}\left(100 \mathrm{MHz}, \mathrm{DMSO}-d_{6}\right), \delta$ (TMS, ppm): 199.07, 146.06, 144.86, $140.63,137.00,131.70,131.55,128.41,125.88,115.09$.

Synthesis of 2-(bis(4-(9H-carbazol-9-yl)phenyl)methylene)malononitrile (1). DCzPT (5.13 g, $10 \mathrm{mmol})$ and malononitrile $(1.43 \mathrm{~g}, 23 \mathrm{mmol})$ were added in a $250 \mathrm{~mL}$ two-neck flask. The mixtures was dissolved in $60 \mathrm{~mL}$ anhydrous chloroform under Ar atmosphere. Then, $4.4 \mathrm{~mL} \mathrm{TiCl}_{4}$ was slowly added into the flask at $0{ }^{\circ} \mathrm{C} .5 \mathrm{~mL}$ pyridine was dropwise added to the reaction mixture and stirred for $2 \mathrm{~h}$ at room temperature. The reaction was quenched with excess distilled water and then extracted with vast TCM and saturated $\mathrm{NaCl}$ solution. The organic layer was dried over $\mathrm{MgSO}_{4}$ and concentrated by a rotary evaporator. The crude product was purified by recrystallization. Yellow-green solid power was obtained in $86.0 \%$ yield. The purified product was characterized using spectra spectroscopic methods. ${ }^{1} \mathrm{H}-\mathrm{NMR}\left(400 \mathrm{MHz}, \mathrm{CDCl}_{3}\right), \delta(\mathrm{TMS}, \mathrm{ppm}): 8.16(\mathrm{~d}, 4 \mathrm{H}), 7.83(\mathrm{~s}, 8 \mathrm{H}), 7.58(\mathrm{~d}, 4 \mathrm{H}), 7.46(\mathrm{td}$, $4 \mathrm{H}), 7.35$ (td, $4 \mathrm{H}) .{ }^{13} \mathrm{C}-\mathrm{NMR}\left(100 \mathrm{MHz}, \mathrm{CDCl}_{3}\right), \delta$ (TMS, ppm): 172.31, 142.29, 139.95, 133.86, 132.41, $126.61,126.37,124.09,121.02,120.58,114.00,109.81,81.60$. HRMS (ESI) $m / z:[\mathrm{M}+]$ calcd. for $\mathrm{C}_{40} \mathrm{H}_{24} \mathrm{~N}_{4}$, 561.2035; found, 560.9629. Crystal Data for 1GC $\left(\mathrm{C}_{40} \mathrm{H}_{24} \mathrm{~N}_{4}\right)$ : orthorhombic, space group P2(1)2(1)2(1), $\mathrm{a}=7.907(2) \AA, \mathrm{b}=14.819(4) \AA, \mathrm{c}=26.414(7) \AA, \beta=90.0^{\circ}, \mathrm{V}=3095.1(13) \AA^{3}, \mathrm{Z}=4, \mathrm{~T}=100.0(2) \mathrm{K}$, $\lambda(\mathrm{Mo} \mathrm{K} \alpha)=\lambda=0.71073 \AA$ Á, Dcalc $=1.203 \mathrm{~g} / \mathrm{cm}^{3}, 17606$ reflections measured $\left(4.132^{\circ} \leq 2 \Theta \leq 50.500^{\circ}\right)$, 5609 unique (Rint $=0.0522)$ which were used in all calculations. The final R1 was $0.0525(\mathrm{I}>2 \sigma(\mathrm{I}))$ and wR2 was 0.1259. Crystal Data for $1 Y C\left(\mathrm{C}_{40} \mathrm{H}_{24} \mathrm{~N}_{4}\right)$ : monoclinic, space group P2(1), a = 10.3034(16) $\AA$, $\mathrm{b}=23.763(4) \AA, \mathrm{c}=13.737(2) \AA, \beta=104.447(3)^{\circ}, \mathrm{V}=3257.0(8) \AA^{3}, \mathrm{Z}=4, \mathrm{~T}=100.0(2) \mathrm{K}, \lambda(\mathrm{Mo} \mathrm{K} \alpha)=\lambda$ $=0.71073 \AA$ Acalc $=1.290 \mathrm{~g} / \mathrm{cm}^{3}, 18,602$ reflections measured $\left(3.428^{\circ} \leq 2 \Theta \leq 50.498^{\circ}\right), 11,381$ unique (Rint $=0.0358)$ which were used in all calculations. The final R1 was $0.0533(\mathrm{I}>2 \sigma(\mathrm{I}))$ and wR2 was 0.1270. Crystal Data for $10 \mathrm{C}\left(\mathrm{C}_{40} \mathrm{H}_{24} \mathrm{~N}_{4}\right)$ : orthorhombic, space group Pbcn, a = 22.459(5) $\AA$, $\mathrm{b}=16.839(4) \AA, \mathrm{c}=7.8968(18) \AA, \beta=90^{\circ}, \mathrm{V}=2986.5(12) \AA^{3}, \mathrm{Z}=4, \mathrm{~T}=100.0(2) \mathrm{K}, \lambda(\mathrm{Mo} \mathrm{K} \alpha)=\lambda$ $=0.71073 \AA$ A , Dcalc $=1.247 \mathrm{~g} / \mathrm{cm}^{3}, 18,984$ reflections measured $\left(3.626^{\circ} \leq 2 \Theta \leq 55.044^{\circ}\right), 3436$ unique $($ Rint $=0.0441)$, which were used in all of the calculations. The final R1 was $0.0407(\mathrm{I}>2 \sigma(\mathrm{I}))$ and wR2 was 0.0875 .

CCDC 1583901 for 1GC, 1583900 for 1YC and 1583902 for 1OC contain the supplementary crystallographic data for this paper. These data can be obtained free of charge from The Cambridge Crystallographic Data Centre via http:/ / www.ccdc.cam.ac.uk/conts/retrieving.html.

\section{Conclusions}

Through introduction of donor and acceptor units to twisted conjugation core, a luminogen (1) exhibiting morphology dependent emission and multicolored emission switching was obtained. Luminogen 1 can form green, yellow-green, and orange emissive crystals, as well as orange emissive amorphous solid. The twisted conformation affords loose packing patterns and facilitates emissive switching through morphology tuning. Luminogen $\mathbf{1}$ exhibits mechanochromic luminescence property, which affords its potential application in security inks and optical recording. More luminogens exhibiting morphology dependent emission and mechanochromic luminescence may be obtained through the combination of D-A units with twisted conformation.

Supplementary Materials: The supplementary materials are available online.

Acknowledgments: This work was partially supported by the National Science Foundation of China (51773020 and 51173018), the Fundamental Research Funds for the Central Universities, and Program for Changjiang Scholars and Innovative Research Team in University.

Author Contributions: H.T. and X.T. performed the experiments and prepared the manuscript; Y.Q.D. designed and guided the research, revised the manuscript. 
Conflicts of Interest: The authors declare no conflict of interest.

\section{References}

1. Hirata, S.; Watanabe, T. Reversible thermo-responsive recording of fluorescent images (TRF). Adv. Mater. 2006, 18, 2725-2729. [CrossRef]

2. Yu, Y.; Yang, J.; Ren, Z.; Xie, G.; Li, Q.; Li, Z. Synthesis of solution processable blue AIEgens and the device performance. Acta Chim. Sin. 2016, 74, 865-870. [CrossRef]

3. Huang, J.; Nie, H.; Zeng, J.J.; Zhuang, Z.Y.; Gan, S.F.; Cai, Y.J.; Guo, J.J.; Su, S.J.; Zhao, Z.J.; Tang, B.Z. Highly efficient nondoped OLEDs with negligible efficiency roll-off fabricated from aggregation-induced delayed fluorescence luminogens. Angew. Chem. Int. Ed. 2017, 56, 12971-12976. [CrossRef] [PubMed]

4. $\quad$ Lin, G.W.; Chen, L.; Peng, H.R.; Chen, S.M.; Zhuang, Z.Y.; Li, Y.H.; Wang, B.H.; Zhao, Z.J.; Tang, B.Z. 3,4-donor- and 2,5-acceptor-functionalized dipolar siloles: Synthesis, structure, photoluminescence and electroluminescence. J. Mater. Chem. C 2017, 5, 4867-4874. [CrossRef]

5. Kishimura, A.; Yamashita, T.; Yamaguchi, K.; Aida, T. Rewritable phosphorescent paper by the control of competing kinetic and thermodynamic self-assembling events. Nat. Mater. 2005, 4, 546-549. [CrossRef] [PubMed]

6. Huang, Y.; Lei, L.; Zheng, C.; Wei, B.; Zhao, Z.; Qin, A.; Hu, R.; Tang Ben, Z. Tetraphenylethene-containing alkynone derivatives: Design and synthesis, aggregation-induced emission characteristics, and the selective fluorescence detection of Pd2+. Acta Chim. Sin. 2016, 74, 885-892. [CrossRef]

7. Ji, G.; Yan, L.; Wang, H.; Ma, L.; Xu, B.; Tian, W. Efficient near-infrared AIE nanoparticles for cell imaging. Acta Chim. Sin. 2016, 74, 917-922. [CrossRef]

8. Peng, Z.; Ji, Y.; Wang, Z.; Tong, B.; Shi, J.; Dong, Y. Properties of polymorphism and acid response of pyrrolopyrrole-based derivative with aggregation-induced emission behavior. Acta Chim. Sin. 2016, 74, 942-948. [CrossRef]

9. Luo, H.Y.; Chen, J.H.; Liu, C.; Shi, G.; Li, G.M.; Chi, Z.G. Synthesis and properties of a multi-functional luminescent material with carbazolyl and tetraphenylethylene moiety. Acta Polym. Sin. 2017, 1277-1284.

10. Yang, P.-P.; Dong, L.-C.; Li, Y.-Y.; Zhang, L.-L.; Shi, J.-B.; Zhi, J.-G.; Tong, B.; Dong, Y.-P. Synthesis and aggregation-enhanced emission of polymethacrylate with pentaphenylpyrrole side group. Acta Polym. Sin. 2017, 8, 1285-1293.

11. Khandare, D.G.; Joshi, H.; Banerjee, M.; Majik, M.S.; Chatterjee, A. An aggregation-induced emission based "turn-on" fluorescent chemodosimeter for the selective detection of Pb2+ ions. RSC Adv. 2014, 4, 47076-47080. [CrossRef]

12. Ma, Y.; Zeng, Y.; Liang, H.; Ho, C.-L.; Zhao, Q.; Huang, W.; Wong, W.-Y. A water-soluble tetraphenylethene based probe for luminescent carbon dioxide detection and its biological application. J. Mater. Chem. C 2015, 3, 11850-11856. [CrossRef]

13. Chen, T.; Chen, Z.-Q.; Gong, W.-L.; Li, C.; Zhu, M.-Q. Ultrasensitive water sensors based on fluorenone-tetraphenylethene AIE luminogens. Mater. Chem. Front. 2017, 1, 1841-1846. [CrossRef]

14. Gan, S.; Zhou, J.; Smith, T.A.; Su, H.; Luo, W.; Hong, Y.; Zhao, Z.; Tang, B.Z. New AIEgens with delayed fluorescence for fluorescence imaging and fluorescence lifetime imaging of living cells. Mater. Chem. Front. 2017, 1, 2554-2558. [CrossRef]

15. Tong, H.; Hong, Y.; Dong, Y.; Haeussler, M.; Lam, J.W.Y.; Li, Z.; Guo, Z.; Guo, Z.; Tang, B.Z. Fluorescent "light-up" bioprobes based on tetraphenylethylene derivatives with aggregation-induced emission characteristics. Chem. Commun. 2006, 35, 3705-3707. [CrossRef] [PubMed]

16. Zhao, Y.; Gao, H.; Fan, Y.; Zhou, T.; Su, Z.; Liu, Y.; Wang, Y. Thermally induced reversible phase transformations accompanied by emission switching between different colors of two aromatic-amine compounds. Adv. Mater. 2009, 21, 3165-3169. [CrossRef]

17. Seeboth, A.; Loetzsch, D.; Ruhmann, R.; Muehling, O. Thermochromic polymers-function by design. Chem. Rev. 2014, 114, 3037-3068. [CrossRef] [PubMed]

18. Ye, Q.; Zhu, D.; Zhang, H.; Lu, X.; Lu, Q. Thermally tunable circular dichroism and circularly polarized luminescence of tetraphenylethene with two cholesterol pendants. J. Mater. Chem. C 2015, 3, 6997-7003. [CrossRef] 
19. Takahashi, E.; Takaya, H.; Naota, T. Dynamic vapochromic behaviors of organic crystals based on the open-close motions of s-shaped donor-acceptor folding units. Chem. Eur. J. 2010, 16, 4793-4802. [CrossRef] [PubMed]

20. Hudson, Z.M.; Sun, C.; Harris, K.J.; Lucier, B.E.G.; Schurko, R.W.; Wang, S. Probing the structural origins of vapochromism of a triarylboron-functionalized platinum(ii) acetylide by optical and multinuclear solid-state NMR spectroscopy. Inorg. Chem. 2011, 50, 3447-3457. [CrossRef] [PubMed]

21. Minei, P.; Koenig, M.; Battisti, A.; Ahmad, M.; Barone, V.; Torres, T.; Guldi, D.M.; Brancato, G.; Bottari, G.; Pucci, A. Reversible vapochromic response of polymer films doped with a highly emissive molecular rotor. J. Mater. Chem. C 2014, 2, 9224-9232. [CrossRef]

22. Mizoshita, N.; Tani, T.; Inagaki, S. Isothermally reversible fluorescence switching of a mechanochromic perylene bisimide dye. Adv. Mater. 2012, 24, 3350-3355. [CrossRef] [PubMed]

23. Zhang, Z.-L.; Yao, D.-D.; Zhou, T.-L.; Zhang, H.-Y.; Wang, Y. Reversible piezo- and photochromic behaviors accompanied by emission color switching of two anthracene-containing organic molecules. Chem. Commun. 2011, 47, 7782-7784. [CrossRef] [PubMed]

24. Zhang, X.; Chi, Z.; Zhang, J.; Li, H.; Xu, B.; Li, X.; Liu, S.; Zhang, Y.; Xu, J. Piezofluorochromic properties and mechanism of an aggregation-induced emission enhancement compound containing $N$-hexyl-phenothiazine and anthracene moieties. J. Phys. Chem. B 2011, 115, 7606-7611. [CrossRef] [PubMed]

25. Zhou, X.; Li, H.Y.; Chi, Z.G.; Zhang, X.Q.; Zhang, J.Y.; Xu, B.J.; Zhang, Y.; Liu, S.W.; Xu, J.R. Piezofluorochromism and morphology of a new aggregation-induced emission compound derived from tetraphenylethylene and carbazole. New J. Chem. 2012, 36, 685-693. [CrossRef]

26. Duan, Y.; Xiang, X.; Dong, Y. Diphenyldibenzofulvene derivatives exhibiting reversible multicolored mechanochromic luminescence with high contrast. Acta Chim. Sin. 2016, 74, 923-928. [CrossRef]

27. Thomas, S.W.; Joly, G.D.; Swager, T.M. Chemical sensors based on amplifying fluorescent conjugated polymers. Chem. Rev. 2007, 107, 1339-1386. [CrossRef] [PubMed]

28. Liu, J.; Lam, J.W.Y.; Tang, B.Z. Acetylenic polymers: Syntheses, structures, and functions. Chem. Rev. 2009, 109, 5799-5867. [CrossRef] [PubMed]

29. Luo, J.D.; Xie, Z.L.; Lam, J.W.Y.; Cheng, L.; Chen, H.Y.; Qiu, C.F.; Kwok, H.S.; Zhan, X.W.; Liu, Y.Q.; Zhu, D.B.; et al. Aggregation-induced emission of 1-methyl-1,2,3,4,5-pentaphenylsilole. Chem. Commun. 2001, 18, 1740-1741. [CrossRef]

30. Tang, B.Z.; Zhan, X.W.; Yu, G.; Lee, P.P.S.; Liu, Y.Q.; Zhu, D.B. Efficient blue emission from siloles. J. Mater. Chem. 2001, 11, 2974-2978. [CrossRef]

31. Hong, Y.; Lam, J.W.Y.; Tang, B.Z. Aggregation-induced emission: Phenomenon, mechanism and applications. Chem. Commun. 2009, 29, 4332-4353. [CrossRef] [PubMed]

32. Dong, Y.; Lam, J.W.Y.; Qin, A.; Li, Z.; Sun, J.; Sung, H.H.Y.; Williams, I.D.; Tang, B.Z. Switching the light emission of (4-biphenylyl)phenyldibenzofulvene by morphological modulation: Crystallization-induced emission enhancement. Chem. Commun. 2007, 1, 40-42. [CrossRef] [PubMed]

33. Dong, Y.Q.; Lam, J.W.Y.; Li, Z.; Qin, A.J.; Tong, H.; Dong, Y.P.; Feng, X.D.; Tang, B.Z. Vapochromism of hexaphenylsilole. J. Inorg. Organomet. Polym. Mater. 2005, 15, 287-291. [CrossRef]

34. Wang, C.; Li, Z. Molecular conformation and packing: Their critical roles in the emission performance of mechanochromic fluorescence materials. Mater. Chem. Front. 2017, 1, 2174-2194. [CrossRef]

35. Peng, L.; Chen, Y.-N.; Dong, Y.Q.; He, C.; Wang, H. Surfactant-assisted self-assembled polymorphs of AIEgen di(4-propoxyphenyl)dibenzofulvene. J. Mater. Chem. C 2017, 5, 557-565. [CrossRef]

36. Lin, Y.; Li, C.; Song, G.; He, C.; Dong, Y.Q.; Wang, H. Freezing-induced multi-colour emissions of AIE luminogen di(4-propoxyphenyl) dibenzofulvene. J. Mater. Chem. C 2015, 3, 2677-2685. [CrossRef]

37. Morris, W.A.; Butler, T.; Kolpaczynska, M.; Fraser, C.L. Stimuli responsive furan and thiophene substituted difluoroboron beta-diketonate materials. Mater. Chem. Front. 2017, 1, 158-166. [CrossRef] [PubMed]

38. Peng, Z.; Huang, K.; Tao, Y.; Li, X.; Zhang, L.; Lu, P.; Wang, Y. Turning on the solid emission from non-emissive 2-aryl-3-cyanobenzofurans by tethering tetraphenylethene for green electroluminescence. Mater. Chem. Front. 2017, 1, 1858-1865. [CrossRef]

39. Wang, F.; DeRosa, C.A.; Daly, M.L.; Song, D.; Sabat, M.; Fraser, C.L. Multi-stimuli responsive luminescent azepane-substituted $\beta$-diketones and difluoroboron complexes. Mater. Chem. Front. 2017, 1, 1866-1874. [CrossRef] 
40. Toal, S.J.; Jones, K.A.; Magde, D.; Trogler, W.C. Luminescent silole nanoparticles as chemoselective sensors for Cr (VI). J. Am. Chem. Soc. 2005, 127, 11661-11665. [CrossRef] [PubMed]

41. Qi, Q.; Liu, Y.; Fang, X.; Zhang, Y.; Chen, P.; Wang, Y.; Yang, B.; Xu, B.; Tian, W.; Zhang, S.X.-A. AIE (AIEE) and mechanofluorochromic performances of TPE-methoxylates: Effects of single molecular conformations. RSC Adv. 2013, 3, 7996-8002. [CrossRef]

42. Zhao, Z.; Chen, T.; Jiang, S.; Liu, Z.; Fang, D.; Dong, Y.Q. The construction of a multicolored mechanochromic luminogen with high contrast through the combination of a large conjugation core and peripheral phenyl rings. J. Mater. Chem. C 2016, 4, 4800-4804. [CrossRef]

43. Tian, H.; Wang, P.; Liu, J.; Duan, Y.; Dong, Y.Q. Construction of a tetraphenylethene derivative exhibiting high contrast and multicolored emission switching. J. Mater. Chem. C 2017, in press. [CrossRef]

44. Shi, J.; Zhao, W.; Li, C.; Liu, Z.; Bo, Z.; Dong, Y.; Dong, Y.; Tang, B.Z. Switching emissions of two tetraphenylethene derivatives with solvent vapor, mechanical, and thermal stimuli. Chin. Sci. Bull. 2013, 58, 2723-2727. [CrossRef]

45. Dong, Y.; Zhang, J.; Tan, X.; Wang, L.; Chen, J.; Li, B.; Ye, L.; Xu, B.; Zou, B.; Tian, W. Multi-stimuli responsive fluorescence switching: The reversible piezochromism and protonation effect of a divinylanthracene derivative. J. Mater. Chem. C 2013, 1, 7554-7559. [CrossRef]

46. Wang, J.; Mei, J.; Hu, R.; Sun, J.Z.; Qin, A.; Tang, B.Z. Click synthesis, aggregation-induced emission, E/Z isomerization, self-organization, and multiple chromisms of pure stereoisomers of a tetraphenylethene-cored luminogen. J. Am. Chem. Soc. 2012, 134, 9956-9966. [CrossRef] [PubMed]

47. Bures, F.; Schweizer, W.B.; May, J.; Boudon, C.; Gisselbrecht, J.-P.; Gross, M.; Biaggio, I.; Diederich, F. Property tuning in charge-transfer chromophores by systematic modulation of the spacer between donor and acceptor. Chem. Eur. J. 2007, 13, 5378-5387. [CrossRef] [PubMed]

48. Nitti, A.; Villafiorita-Monteleone, F.; Pacini, A.; Botta, C.; Virgili, T.; Forni, A.; Cariati, E.; Boiocchi, M.; Pasini, D. Structure-activity relationship for the solid state emission of a new family of "push-pull" $\pi$-extended chromophores. Faraday Discuss. 2017, 196, 143-161. [CrossRef] [PubMed]

49. Botta, C.; Benedini, S.; Carlucci, L.; Forni, A.; Marinotto, D.; Nitti, A.; Pasini, D.; Righetto, S.; Cariati, E. Polymorphism-dependent aggregation induced emission of a push-pull dye and its multi-stimuli responsive behavior. J. Mater. Chem. C 2016, 4, 2979-2989. [CrossRef]

50. Dong, Y.; Xu, B.; Zhang, J.; Tan, X.; Wang, L.; Chen, J.; Lv, H.; Wen, S.; Li, B.; Ye, L.; et al. Piezochromic luminescence based on the molecular aggregation of 9,10-bis((E)-2-(pyrid-2-yl)vinyl)anthracene. Angew. Chem. Int. Ed. 2012, 51, 10782-10785. [CrossRef] [PubMed]

51. Yoon, S.-J.; Chung, J.W.; Gierschner, J.; Kim, K.S.; Choi, M.-G.; Kim, D.; Park, S.Y. Multistimuli two-color luminescence switching via different slip-stacking of highly fluorescent molecular sheets. J. Am. Chem. Soc. 2010, 132, 13675-13683. [CrossRef] [PubMed]

52. Yuan, W.Z.; Tan, Y.; Gong, Y.; Lu, P.; Lam, J.W.Y.; Shen, X.Y.; Feng, C.; Sung, H.H.Y.; Lu, Y.; Williams, I.D.; et al. Synergy between twisted conformation and effective intermolecular interactions: Strategy for efficient mechanochromic luminogens with high contrast. Adv. Mater. 2013, 25, 2837-2843. [CrossRef] [PubMed]

53. Chen, M.; Li, L.; Nie, H.; Tong, J.; Yan, L.; Xu, B.; Sun, J.Z.; Tian, W.; Zhao, Z.; Qin, A.; et al. Tetraphenylpyrazine-based AIEgens: Facile preparation and tunable light emission. Chem. Sci. 2015, 6, 1932-1937. [CrossRef] [PubMed]

54. Wang, Y.; Zhang, G.; Zhang, W.; Wang, X.; Wu, Y.; Liang, T.; Hao, X.; Fu, H.; Zhao, Y.; Zhang, D. Tuning the solid state emission of the carbazole and cyano-substituted tetraphenylethylene by co-crystallization with solvents. Small 2016, 12, 6554-6561. [CrossRef] [PubMed]

Sample Availability: Samples of the compound (2-(bis(4-(carbazol-9-yl)phenyl)methylene)malononitrile (1) are available from the authors.

(C) 2017 by the authors. Licensee MDPI, Basel, Switzerland. This article is an open access article distributed under the terms and conditions of the Creative Commons Attribution (CC BY) license (http:/ / creativecommons.org/licenses/by/4.0/). 